\title{
Comparison of oral health condition in Polish adolescents within 7 years
}

\section{Porównanie stanu zdrowia jamy ustnej młodzieży polskiej w okresie 7 lat}

\author{
Dorota Olczak-Kowalczyk ${ }^{1, A, B, D-F}$, Dariusz Gozdowski2, ${ }^{2, E}$, Elżbieta Małkiewicz ${ }^{3, A, E}$, Urszula Kaczmarek ${ }^{4, B-F}$ \\ ${ }^{1}$ Department of Pediatric Dentistry, Faculty of Medicine and Dentistry, Medical University of Warsaw, Poland \\ ${ }^{2}$ Department of Experimental Design and Bioinformatics, Faculty of Agriculture and Biology, Warsaw University of Life Sciences, Poland \\ ${ }^{3}$ Department of Mother and Child, Ministry of Health, Warszawa, Poland \\ ${ }^{4}$ Department of Conservative Dentistry and Pedodontics, Faculty of Dentistry, Wroclaw Medical University, Poland \\ A - research concept and design; $\mathrm{B}$ - collection and/or assembly of data; $\mathrm{C}$ - data analysis and interpretation; \\ $D$ - writing the article; $E$ - critical revision of the article; $F$ - final approval of the article
}

Address for correspondence

\section{Urszula Kaczmarek}

E-mail: urszula.kaczmarek@umed.wroc.pl

Funding sources

None declared

Conflict of interest

None declared

Received on July 13, 2018

Reviewed on August 19, 2018

Accepted on September 25, 2018

Published online on December 20, 2018

Cite as

Olczak-Kowalczyk D, Gozdowski D, Małkiewicz E, Kaczmarek U. Comparison of oral health condition in Polish adolescents within 7 years. Dent Med Probl. 2018;55(4):399-404. doi:10.17219/dmp/96273

DOI

$10.17219 / \mathrm{dmp} / 96273$

Copyright

() 2018 by Wroclaw Medical University

and Polish Dental Society

This is an article distributed under the terms of the

Creative Commons Attribution Non-Commercial License

(http://creativecommons.org/licenses/by-nc-nd/4.0/)

\begin{abstract}
Background. There is some increase in the risk of oral diseases in adolescence, as in this period of life, individuals become more independent regarding the consumption of sugary food and beverages, and they can be reluctant to apply oral hygiene procedures systematically. Therefore, adolescence is a period of life that needs special attention.

Objectives. The objective of this study was to compare some oral health parameters and oral health-related behaviors of 15 -year-olds within the past 7 years.

Material and methods. In 2008 and 2015, nationwide surveys on oral health condition involving 15-year-olds were carried out in Poland. Sampling and clinical examinations were performed according to the World Health Organization (WHO) criteria, which were extended with a questionnaire concerning pro-health behaviors.

Results. Caries prevalence and severity turned out to be a constant, as neither a significant reduction in the proportion of caries-affected adolescents (94.0\% vs $94.0 \%$ ) nor in the decayed, missing and filled teeth (DMFT) (5.96 vs 5.65), DT, FT, and significant caries (SiC) index values was found, except for a decline in MT $(0.17$ vs $0.07 ; p<0.05)$. The periodontal condition revealed deterioration, since some increase in the percentage of adolescents with gingival bleeding (34.2\% vs $37.4 \%$ ), shallow pockets ( 0 vs $2.8 \%$ ) and loss of attachment ( 0 vs $1.3 \%)$, and a decrease in the mean number of sound sextants ( 4.85 vs $4.21 ; p<0.01$ ) were noticed. Moreover, fewer adolescents declared brushing their teeth at least twice a day $(77.8 \%$ vs $66.7 \% ; p<0.001)$.
\end{abstract}

Conclusions. The high and constant prevalence of caries and deterioration of the periodontal condition indicate a significant burden on the oral health of adolescents. To improve this situation, the implementation of proper age-oriented oral health programs is needed.

Key words: adolescents, caries prevalence, periodontal condition

Słowa kluczowe: młodzież, występowanie próchnicy, stan przyzębia 


\section{Introduction}

The World Health Organization (WHO) defines adolescents as subjects between 10 and 19 years of age. Adolescence is the phase of life in which individuals are in biological, psychological and social development, and assume adult roles. ${ }^{1}$ Overall, they present the best general health. However, there is some increase in the risk to oral health in this period of life, since adolescents are more independent regarding the consumption of sugary food and beverages, and can be reluctant to apply oral hygiene procedures systematically. Therefore, it is a period of life requiring special attention.

Dental caries and periodontal diseases, being the main oral diseases, are widespread in various populations, and are age-related and cumulative diseases. Therefore, for national and international comparisons of oral health in the populations, the WHO recommends the examination of the specific age groups. Among adolescents, the individuals at the age of 12 and 15 years constitute the selected age groups. The most often examined age group are 12-year-olds due to the likelihood of having all the permanent teeth, with the exception of the third permanent molars, and because of being easily available for oral examination on the primary school basis. Therefore, this age group has been chosen as the global indicator. However, individuals at the age of 15 are also valid, because they have all their permanent teeth erupted, except for the third molars, and exposed to the oral environment for 3-9 years, and they have established oral hygiene and dietary habits. Thus, it makes the assessment of caries and periodontal diseases relevant and important. ${ }^{2}$

Dental caries is a chronic and multifactorial disease, developing the most frequently in children and adolescents, still people remain vulnerable to the disease for their whole lives. However, it is a preventable disease, because it can be stopped or even reversed at its early stage with the use of simple measures, i.e., by dental biofilm removal, reduction of sugary food consumption and topical fluoride applications. A number of factors have been recognized to have a modulating effect on oral health, among others, behavioral ones (e.g., proper tooth brushing, use of fluoridated toothpaste, reduction of consumption of fermentable carbohydrates), oral health-related knowledge, regular dental check-ups, the socioeconomic status, and ethnicity. ${ }^{3-5}$ Caries prevalence among 15-year-olds is very differentiated, ranging from $21.9 \%$ to $97.6 \%$ of affected subjects with the involvement of 0.7 (Malawi) to 8.1 teeth (Latvia).,7

At this age, periodontal diseases occur less frequently compared to dental caries. The data from the WHO Periodontal Profile showed that acute gingivitis occurred predominantly, manifesting itself as bleeding on probing, present in $1 \%$ (Benin, 2003) to $51 \%$ of subjects (Germany, 2005). Calculus was noticed in $13.0 \%$ (Djibouti, 1988) to $92 \%$ of subjects (Kyrgyzstan, 1987). The presence of gin- gival pockets was quite low, and was noted for 0 (Benin, 2003; Spain, 2005; Namibia, 2013) to $15 \%$ of subjects (Belarus, 2000/1). Healthy periodontium was observed in 0 (Belarus, 2000/1) to $46 \%$ of subjects. (Benin, 2003). ${ }^{8}$

The aim of the study was to compare some oral health parameters and oral health-related behaviors of 15-yearolds within the past 7 years.

\section{Material and methods}

Data for the analysis was obtained from 2 cross-sectional nationwide surveys, which were conducted in 2008 and 2015; both entitled Monitoring of Oral Health.9,10 The population groups were selected by a 3 -stage cluster sampling procedure, including 1,839 subjects in 2008, living in urban and rural areas of 16 provinces, and 615 subjects in 2015 from urban and rural areas of 3 provinces situated in western, central and eastern parts of Poland. Despite the 3-fold lower number of the examined individuals in the $2^{\text {nd }}$ survey, a sample of about 600 subjects presented the minimum representative sample size. It was calculated taking into account the data on the total number of 15-year-olds retrieved from the Statistics Poland (Demographic Yearbook of Poland 2014) and caries prevalence in this age group in Poland $(90 \% \pm 2.5 \%$ error tolerance at $95 \%$ confidence interval (CI)). The participation in both surveys was voluntary. The examined groups in 2008 and 2015 comprised approximately equal numbers of males and females $(46.0 \%$ and $54.0 \%$ vs $40.7 \%$ and $59.3 \%$, respectively) and similar numbers of residents of urban and rural areas $(47.7 \%$ and $52.3 \%$ vs $54.3 \%$ and $45.7 \%$, respectively). In both surveys, the inclusive criteria were the same, i.e., the age of 15 years, the parents' signed consent, a completed questionnaire, and the compliancy of the adolescent. Likewise, the exclusive criteria were the opposite: age of less or more than 15 years, no parental signed consent, an uncompleted questionnaire, and an uncooperative attitude of the adolescent. Finally, the adolescents were enrolled in the survey based on school class attendance.

Both surveys consisted of clinical oral examination and a structured questionnaire; however, the items in these questionnaires were slightly different. Therefore, it was possible to compare only the same parameters, contained in both surveys.

The oral examination was conducted with the use of artificial light, a plane mirror and a ball-ended dental probe (WHO-621 periodontal probe) by the dentists who had been trained and calibrated. In each subject, the parameters of oral health condition were recorded according to the WHO criteria. ${ }^{2,11}$ Dental caries was diagnosed at the cavitation level. Caries experience was registered in terms of the decayed, missing and filled teeth (DMFT) index value and its components, as well as the significant caries $(\mathrm{SiC})$ index. The CARE-Index 
(FT / DMFT $\times 100 \%$ ), assessing the proportion of teeth that have received restorative care, was calculated.

In 2008, the periodontal status was assessed according to the community periodontal index (CPI) criteria, registering the condition around the index teeth in 6 sextants as sound, bleeding on probing, presence of calculus, shallow and deep periodontal pockets, and loss of epithelial attachment. ${ }^{9,11}$ In the $2^{\text {nd }}$ study, the periodontal condition was assessed using the modified CPI, which registered bleeding on probing and the depth of pockets around all the examined teeth, as well as loss of epithelial attachment. ${ }^{2,10}$

The self-reported questionnaire in both studies contained the same items regarding the frequency of tooth brushing, consumption of sugary beverages, the date of the last dental visit, counseling obtained from the dentist, self-assessment of oral health, and 3 questions concerning the oral health-related knowledge:

- Does caries develop more quickly in children and adolescents than in adults?

- If parents have a great number of carious lesions, will their children also have dental caries, no matter if they take care of their teeth or not?

- Does fluoride use make the enamel resistant to caries?

Both surveys received the consent of the Bioethics Committee of the Warsaw Medical University of July 20, 2008 and August 18, 2015.

Statistical analysis of the data was carried out using the $\chi^{2}$ test at a significance level of $p<0.05$ in Statistica v. 10.0 software (StatSoft Polska Sp. z o.o., Kraków, Poland).

\section{Results}

The percentage of caries-affected subjects remained at the same level of $94.0 \%$. The mean caries level expressed as mean DMFT decreased by about $6 \%$. The $\mathrm{SiC}$ index was over 2.5-fold higher than DMFT for the remaining $2 / 3$ of adolescents in both surveys. Some slight changes were observed in DT, MT and FT components. In 2015, the mean DT value increased by about $8 \%$ in comparison to 2008 . The FT value declined by about $7 \%$. The value of the CARE-Index remained nearly the same. However, the mean number of missing teeth was reduced significantly, over 2 -fold (Table 1 ).

The percentage of children with at least 1 tooth extracted due to caries was reduced nearly by a half. However, the percentage of adolescents with DT $\leq 1$ and with at least 1 tooth sealed increased slightly. On the other hand, the percentage of adolescents with DT $\geq 1$ and at least 1 tooth with pit and fissure sealant rose slightly. The mean number of teeth with pit and fissure sealants in the subjects was reduced (Table 2).

The periodontal condition seemed to deteriorate, as evidenced in the $2^{\text {nd }}$ survey. The frequency of gingival bleeding $(3.2 \%)$, shallow gingival pocket $(2.8 \%)$ and loss of attachment (1.3\%) increased. The mean number of sound sextants decreased significantly (Table 3 ).

Within the past 7 years, the percentage of adolescents who declared brushing their teeth at least twice a day diminished significantly from $77.8 \%$ to $66.7 \%$. In contrast, the percentage of the subjects cleaning their teeth once

Table 1. Means of the decayed, missing and filled teeth (DMFT) index values and DMFT components

\begin{tabular}{|l|c|c|c|cc|c|c|}
\hline Survey & DMFT & DT & MT & FT & SiC & DMFT for 2/3 & CARE-Index \\
\hline 2008 & 5.96 & 2.03 & 0.17 & 3.76 & 3.67 & 10.08 & 3.1 \\
2015 & 5.65 & 2.20 & 0.07 & 3.48 & 9.96 & 3.56 \\
$p$-value & $>0.05$ & $>0.05$ & $<0.05^{*}$ & $>0.05$ & $>0.05$ & $>0.05$ \\
\hline
\end{tabular}

$\mathrm{SiC}$ - the significant caries index; ${ }^{*}$ statistically significant difference.

Table 2. Percentage of subjects with at least 1 decayed, missing or sealed tooth

\begin{tabular}{|c|c|c|c|c|}
\hline \multirow{2}{*}{ Survey } & \multicolumn{3}{|c|}{ At least 1 tooth } & \multirow{2}{*}{$\begin{array}{l}\text { Mean number of teeth with pit and fissure } \\
\text { sealant in the subjects with sealed teeth }\end{array}$} \\
\hline & with decay & missed due to caries & with pit and fissure sealant & \\
\hline 2008 & 60.7 & 10.8 & 19.7 & 3.09 \\
\hline 2015 & 62.8 & 5.0 & 21.1 & 2.20 \\
\hline$p$-value & $>0.05$ & $<0.001^{*}$ & $>0.05$ & $<0.05^{*}$ \\
\hline
\end{tabular}

* statistically significant difference.

Table 3. Periodontal condition of the subjects

\begin{tabular}{|l|c|c|c|c|}
\multirow{2}{*}{ Survey } & \multicolumn{4}{|c|}{ Percentage of subjects according to the periodontal condition } \\
\cline { 2 - 5 } & sound & bleeding on probing & shallow pockets (4-5 mm) & loss of attachment (4-5 mm) \\
\hline 2008 & 63.1 & 34.2 & 0 & 0 \\
2015 & 58.5 & 37.4 & 2.8 & 4.85 \\
$p$-value & $>0.05$ & $>0.05$ & - & 4.21 \\
\hline
\end{tabular}

* statistically significant difference. 
a day increased significantly (from $16.8 \%$ to $26.2 \%$ ) and the percentage of those brushing their teeth sporadically rose slightly (from $5.4 \%$ to $7.1 \%$ ). Frequent consumption of sweetened beverages remained on the same level (20\%). Slightly more adolescents reported having at least 1 dental appointment during the last 12 months. Regarding the counsel offered by dentists, the $2^{\text {nd }}$ survey indicated that they paid less attention to simple domestic preventive measures recommended to their young patients, especially cariostatic dietary habits, the use of fluoridated toothpaste and a schedule of check-ups, appropriately to the risk of caries.

Oral health-related knowledge in 2015 seemed to be more widespread. Approximately $7 \%$ more adolescents answered all 3 questions correctly. However, significantly fewer of the surveyed believed that fluoride makes dental enamel resistant to caries. In the $2^{\text {nd }}$ survey, the adolescents assessed the condition of their teeth more realistically, as fewer of them considered it very good or good (Table 4).

\section{Discussion}

The comparison of the nationwide epidemiological data within the period of 7 years indicated that dental caries still remains a great burden in the Polish population at the age of 15 years. The caries level seemed to be steady. The only positive change was a significant diminution in the MT value and over a 2-fold reduction in the percentage of youth with at least 1 missing tooth due to caries. In contrast to our data, a substantial reduc- tion of dental caries in other countries was observed. In the period from 1993 to 1998, 14.4\% increase in cariesfree 15-year-olds and ca. 22\% decrease in DMFT (from 5.60 to 4.33 ) in Slovenia was noticed. ${ }^{12}$ In Switzerland, in the canton of Zürich, the DMFT value also decreased by ca. $22 \%$, from 2.02 in 1996 to 1.58 in $2000,{ }^{13}$ and in the canton of Basel-Landschaft by ca. 43\% from 3.3 in 1977 to 1.72 in $2011 .{ }^{4}$ However, in Lithuania, after some drop in DMFT between 1983 and 1995 (from 6.42 to 6.07), a slight increase was noticed in the last study (5.39 in 2000 vs 5.58 in 2005). ${ }^{14}$ In Australia, the mean DMFT values for 14- and 15-year-olds have remained fairly stable over the last decade. ${ }^{15}$

The $\mathrm{SiC}$ index below 5 was suggested by Marthaler et al. to be the global goal for the 15 -year-olds..$^{13}$ In Switzerland, the $\mathrm{SiC}$ index value dropped from 4.91 in 1996 to 4.31 in $2000 .{ }^{13}$ However, Waltimo et al., studying Swiss and foreign children, noticed a slight increase in the $\mathrm{SiC}$ index value from 3.94 in 2006 to 4.39 in 2011 (ca. 10\%) after a decrease in the previous years. ${ }^{4}$ In contrast, our data presented almost no change in this index value within the last 7 years. The improvement of dental health was explained by the effectiveness of the preventive programs implemented in those countries. ${ }^{4,12,13}$ In Poland, dental care for individuals up to the age of 18 years is free. Therefore, each child can benefit from routine dental treatment and preventive measures, including pit and fissure sealant placement on first permanent molars and the application of fluoride varnish every 3 months, check-up oral examinations with oral hygiene instruction twice a year, some preventive packages directed to specific age groups, as well as supervised tooth brushing

Table 4. Behaviors, oral health-related knowledge and self-assessment of dental health

\begin{tabular}{|c|c|c|c|c|}
\hline \multirow{2}{*}{\multicolumn{2}{|c|}{ Parameters }} & \multicolumn{2}{|c|}{ Survey } & \multirow{3}{*}{$\begin{array}{l}p \text {-value } \\
<0.001^{*}\end{array}$} \\
\hline & & \multirow{2}{*}{$\begin{array}{c}2008 \\
77.8\end{array}$} & \multirow{2}{*}{$\begin{array}{r}2015 \\
66.7\end{array}$} & \\
\hline \multirow{3}{*}{ Frequency of tooth brushing } & at least twice a day & & & \\
\hline & once a day & 16.8 & 26.2 & $<0.001^{*}$ \\
\hline & less frequently & 5.4 & 7.1 & $>0.05$ \\
\hline \multirow{2}{*}{ Consumption of sugared beverages } & at least once a day & 20.0 & 20.1 & $>0.05$ \\
\hline & less frequently & 80.0 & 79.9 & $>0.05$ \\
\hline \multirow{2}{*}{ Last dental visit } & within 12 months & 77.8 & 81.1 & $>0.05$ \\
\hline & over 12 months ago & 22.2 & 18.9 & $>0.05$ \\
\hline \multirow{4}{*}{ Advice received from a dentist regarding } & cariostatic dietary regimen & 17.9 & 11.7 & $<0.001^{*}$ \\
\hline & teeth cleaning & 39.0 & 38.5 & $>0.05$ \\
\hline & fluoridated toothpaste use & 29.0 & 10.4 & $<0.001^{*}$ \\
\hline & schedule of check-ups & 54.9 & 46.5 & $<0.001^{*}$ \\
\hline \multirow{3}{*}{ Oral health knowledge (correct response) } & question 1 & 66.4 & 67.6 & $>0.05$ \\
\hline & question 2 & 47.5 & 77.4 & $<0.001^{*}$ \\
\hline & question 3 & 65.5 & 54.5 & $<0.001^{*}$ \\
\hline \multirow{3}{*}{ Self-rated dental health } & very good/good & 82.4 & 64.0 & $<0.001^{*}$ \\
\hline & satisfied & no data & 27.2 & - \\
\hline & poor & 17.6 & 8.8 & $<0.001^{*}$ \\
\hline
\end{tabular}

Data expressed as percentages; ${ }^{*}$ statistically significant difference. 
with the use of fluoride gel in primary schools. However, such availability of dental care did not yield the expected satisfactory results.

In caries prevention, the efficacy in caries prevention of the sealants placement on occlusal surface of the most caries-prone permanent first molars has been indicated. ${ }^{16,17}$ In countries with low caries prevalence, like Denmark, ca. 2/3 of 15-year-old adolescents had at least 1 sealed molar. ${ }^{18}$ In both our surveys, the percentage of adolescents with at least 1 tooth sealed was lower and almost the same in 2008 and 2015. A similar proportion of Polish and English 15-year-olds revealed the presence of pit and fissure sealants $(21.1 \%$ vs $22.0 \%)$, but the percentages were higher in the case of adolescents from Wales and Northern Ireland (28.0\% and 34.0\%, respectively). ${ }^{19}$ In Greece, only $8.0 \%$ of 15 -year-olds had at least 1 sealed molar. This has been attributed to the lack of public awareness and dentists not being convinced of the usefulness and effectiveness of pit and fissure sealants in caries prevention. ${ }^{20}$

The comparison of data from both our surveys revealed some deterioration in the periodontal condition, as we observed a slight increase in the frequency of gingival bleeding and the occurrence of shallow gingival pockets, loss of epithelial attachment and a significant reduction in the mean number of sextants with sound periodontium. The proportion of 15-year-olds with gingival bleeding varied in different countries from $25 \%$ to $92 \% .{ }^{5,7,19,21-23}$ Gingival bleeding evaluated by the application of a periodontal probe around 6 index teeth within 10 years (2003-2013) decreased in England (from $45 \%$ to $40 \%$ ) and Northern Ireland (from $44 \%$ to $41 \%$ ), but increased in Wales (from $37 \%$ to $42 \%) .{ }^{19}$ However, taking into consideration our data, the occurrence of shallow pockets was greater than in Greece $-0.2 \%{ }^{23}$ and smaller than in Georgia $-35.36 \%{ }^{22}$

The proportion of Polish adolescents who reported brushing their teeth twice a day or more often was higher in 2008 than in 2015. In contrast, in England, Wales and Northern Ireland, it increased from $80 \%$ in 2003 to $85 \%$ in $2013 .{ }^{24}$ In 2015 , dental floss was used by $46.5 \%$ of Polish adolescents and $11.4 \%$ of them declared using sugar-free chewing gums. ${ }^{10}$ In comparison to those figures, 15-yearolds living in England, Wales and Northern Ireland used dental floss less frequently (21\%) and more often chose sugar-free chewing gum (34\%). ${ }^{24}$

The exemplary sugary products were different in both our studies; therefore, we could not make any comparison. We were able to compare only the frequency of sweetened beverage consumption on the level 'at least once a day', which turned out to be the same. In contrast to our data, fewer adolescents living in England, Wales and Northern Ireland (14\%) reported consumption of sugary drinks 4 or more times a day. In England, Wales and Northern Ireland, 86\% 15-year-olds reported that during the last dental appointment they were provided with preventative counseling. ${ }^{24} \mathrm{~A}$ retrospective evaluation of the provision of different types of preventive care for 15-year-olds in Australia revealed that only $7.9 \%$ of them were provided with dietary advice and $14.3 \%$ with oral hygiene instruction. ${ }^{25}$ Our surveys also revealed that dentists in Poland rarely offered preventative counseling to their patients. A decreased percentage of adolescents were informed about the benefits of fluoride in toothpaste and got dietary counseling. This implies the need to strengthen guidance concerning the preventive role of dentists working in primary dental care units.

In the $2^{\text {nd }}$ survey compared to the $1^{\text {st }}$ one, the adolescents more realistically assessed the condition of their teeth, as fewer of them recognized it as very good or good (64.0\% vs $82.4 \%)$. The national surveys conducted in England, Wales and Northern Ireland indicated the percentage of 15-year-olds satisfied with the appearance of their teeth ranged from 54\% (Wales) to 61\% (England and Northern Ireland each). Besides, Polish surveys regarding the appearance of teeth did not provide an example of the concept of appearance (e.g., white teeth, straight teeth). ${ }^{21}$

In 2015, 81.1\% of Polish adolescents reported to have a dental visit in the last 12 months; it was slightly more than 7 years earlier (by 3.3\%). In contrast, more 15-yearolds from England, Northern Ireland and Wales visited a dentist the previous year (90\%, 95\% and 96\%, respectively) having the DT value ca. 3-4 times lower in comparison to Polish adolescents $(0.5,0.8$ and 0.8 vs 2.2 , respectively). ${ }^{19}$

\section{Conclusions}

The data indicated that within the last 7 years, oral health parameters in 15-year-old adolescents did not improve, except for the reduction of missed teeth due to caries as well as oral health-related behaviors. Moreover, such a situation suggests that the currently used preventive measures are not effective and, therefore, there is a need to implement broad age-based oral health promotion and prevention.

\section{References}

1. WHO. Adolescence: A period needing special attention. http:// apps.who.int/adolescent/second-decade/section2/page1/recognizing-adolescence.html. Accessed July 11, 2018.

2. WHO. Oral Health Surveys. Basic Methods. $5^{\text {th }}$ ed. Geneva, Switzerland: World Health Organization; 2013.

3. Campus G, Cagetti MG, Senna A, Sacco G, Strohmenger L, Petersen PE. Caries prevalence and need for dental care in 13-18-yearolds in the Municipality of Milan, Italy. Community Dent Health. 2008;25:237-242.

4. Waltimo T, Menghini G, Weber C, Kulik EM, Schild S, Meyer J. Caries experience in 7-, 12-, and 15-year-old schoolchildren in the canton of Basel-Landschaft, Switzerland, from 1992 to 2011. Community Dent Oral Epidemiol. 2016;44:201-208.

5. Rebelo MA, Lopes MC, Vieira JM, Parente RC. Dental caries and gingivitis among 15- to 19-year-old students in Manaus, AM, Brazil. Braz Oral Res. 2009;23:248-254.

6. Msyamboza KP, Phale E, Namalika JM, et al. Magnitude of dental caries, missing and filled teeth in Malawi: National Oral Health Survey. BMC Oral Health. 2016;16:29. doi:10.1186/s12903-016-0190-3

7. Bjarnason S, Berzina S, Care R, Mackevica I, Rence I. Oral health in Latvian 15-year-olds. Eur J Oral Sci. 1995;103:274-279. 
8. WHO Periodontal country profiles. http://www.dent.niigata-u. ac.jp/prevent/perio/contents.html. Accessed July 11, 2018.

9. Jodkowska E, Wierzbicka M, Szatko F, et al. Stan zdrowia jamy ustnej dzieci i młodzieży. Monitoring zdrowia jamy ustnej. Polska 2018. Warsaw, Poland: Medical University of Warsaw Press; 2008:31-49,75-79.

10. Olczak-Kowalczyk D, Kaczmarek U, Kawala B, et al. Monitoring zdrowia jamy ustnej. Monitorowanie stanu zdrowia jamy ustnej populacji polskiej w latach 2013-2015. Ocena stanu zdrowia jamy ustnej i jego uwarunkowań w populacji polskiej w wieku 3, 10 i 15 lat. Polska 2015. Warsaw, Poland: Medical University of Warsaw Press; 2015:178-197,211-214,261-287.

11. WHO. Oral Health Surveys. Basic Methods. $4^{\text {th }}$ ed. Geneva, Switzerland: World Health Organization; 1997.

12. Vrbič V. Reasons for the caries decline in Slovenia. Community Dent Oral Epidemiol. 2000;28:126-132.

13. Marthaler T, Menghini G, Steiner M. Use of the Significant Caries Index in quantifying the changes in caries in Switzerland from 1964 to 2000. Community Dent Oral Epidemiol. 2005;33:159-166.

14. Milčiuviené $S$, Bendoraitiené $E$, Andruškevičiené $V$, et al. Caries dental prevalence among 12-15-year-olds in Lithuania between 1983 and 2005. Medicina (Kaunas). 2009;45:68-76.

15. Skinner J, Johnson G, Phelan C, Blinkhorn A. Dental caries in 14and 15-year-olds in New South Wales, Australia. BMC Public Health 2013;13:1060.

16. Hiiri A, Ahovuo-Saloranta A, Nordblad A, Mäkelä M. Pit and fissure sealants versus fluoride varnishes for preventing dental decay in children and adolescents. Cochrane Database Syst Rev. 2006;4:CD003067.

17. Ahovuo-Saloranta A, Forss $\mathrm{H}$, Hiiri A, Nordblad A, Mäkelä M. Pit and fissure sealants versus fluoride varnishes for preventing dental decay in the permanent teeth of children and adolescents. Cochrane Database Syst Rev. 2016;1:CD003067.

18. Ekstrand KR, Martignon S, Christiansen ME. Frequency and distribution patterns of sealants among 15-year-olds in Denmark in 2003. Community Dent Health. 2007;24:26-30.

19. Children's Dental Health Survey 2013. Report 2: Dental disease and damage in children. England, Wales and Northern Ireland. Health and Social Care Information Centre. 2015. http://www.hscic.gov. uk/catalogue/PUB17137/CDHS2013-Report2-Dental-Disease.pdf. Accessed July 11, 2018.

20. Oulis CJ, Berdouses ED, Mamai-Homata E, Polychronopoulou A. Prevalence of sealants in relation to dental caries on the permanent molars of 12- and 15-year-old Greek adolescents. A national pathfinder survey. BMC Public Health. 2011;11:100.

21. Yazdani R, Vehkalahti MM, Nouri M, Murtomaa H. Validity of selfassessment of oral health among 15 -year-olds in Tehran, Iran. Oral Health Prev Dent. 2008;6:263-269.

22. Levin L, Margvelashvili V, Bilder L, Kalandadze N, Machtei EE. Periodontal status among adolescents in Georgia. A pathfinder study. Peer J. 2013;1:e137.

23. Vadiakas G, Oulis CJ, Tsinidou K, Mamai-Homata E, Polychronopoulou A. Oral hygiene and periodontal status of 12- and 15-year-old Greek adolescents. A national pathfinder survey. Eur Arch Paediatr Dent. 2012;13:11-20.

24. Children's Dental Health Survey 2013. Report 1: Attitudes, behaviours and children's dental health. England, Wales and Northern Ireland. Health and Social Care Information Centre. 2015. http:// content.digital.nhs.uk/catalogue/PUB17137/CDHS2013-Report1Attitudes-and-Behaviours.pdf. Accessed July 11, 2018.

25. Masoe AV, Blinkhorn AS, Taylor J, Blinkhorn FA. Preventive and clinical care provided to adolescents attending public oral health services New South Wales, Australia: A retrospective study. BMC Oral Health. 2014;14:142. 